\title{
IMAGENS DE CRIANÇAS E CRIANÇAS NAS IMAGENS: REPRESENTAÇÕES DA INFÂNCIA NA ICONOGRAFIA PEDAGÓGICA NOS SÉCULOS XVII E XVIII*
}

\author{
LOIC CHALMEL $^{* *}$
}

\begin{abstract}
RESUMO: O texto discute a trajetória das representações da infância do Século das Luzes (XVII), quando o humanismo originou mudanças na representação da infância, antes sacra e que então se torna real, e as do século XVIII, no qual uma infância idealizada esconde a rudeza da vida real das crianças da época, para afunilar este debate na produção iconográfica com objetivos pedagógicos. Da produção imagética proposta por Comenius ao que se fez a partir dele no século seguinte, destaca-se a permanência da idéia do uso da imagem como representação do real, de leitura e compreensão mais fáceis que o código escrito, sendo, portanto, uma ferramenta pedagógica útil. Ao mesmo tempo, discute-se o significado das mudanças operadas nas imagens como representativo de mudanças nos modos de pensar e de conceber o próprio conhecimento e seus processos de transmissão.
\end{abstract}

Palavras-chave: Infância. Produção iconográfica. Ferramenta pedagógica.

\section{IMAGES OF CHILDREN AND CHILDREN IN PICTURES: REPRESENTATIONS OF CHILDHOOD IN THE EDUCATIONAL ICONOGRAPHY IN THE XVII ${ }^{\mathrm{TH}}$ AND XVIII ${ }^{\mathrm{TH}}$ CENTURIES}

ABSTRACT: This text discusses how childhood was represented in the XVII ${ }^{\text {th }}$ century, when Humanism determined a shift from sacred models to real ones, and in the XVIII ${ }^{\text {th }}$ century, when idealized images of childhood hid the children's real conditions of living, in order to analyze the evolution of image production for pedagogical purposes. From Comenius on, the prevalent conception of image

* Tradução de Alain François, com revisão técnica de Inês Barbosa de Oliveira.

** Doutor em Educação e professor assistente habilitado para orientar pesquisas da Universidade de Rouen (França). E-mail: loic.chalmel@fnac.fr

Educ. Soc., Campinas, vol. 25, n. 86, p. 57-74, abril 2004

Disponível em <http://www.cedes.unicamp.br> 
Imagens de crianças e crianças nas imagens: representaçōes da infância...

has been the representation of the real world, easier to read and understand than the written language and, therefore, useful as a pedagogical device. The text also discusses the meaning of the changes in such images as representative of the changes in the ways of thinking and conceiving knowledge itself and its transmission procedures.

Key words: Childhood. Image production. Pedagogical tool.

Da criança imagem...

Cria o Século das Luzes, na Europa, um período-chave na evolução das representações da criança na arte em geral? Sem dúvida, neste quesito, é preciso evitar associar novidade e modernidade. Decerto, os retratos de Elisabeth Vigée Lebrun (1755-1842) ou ainda os de Jean-Honoré Fragonard (1732-1806) demarcam claramente essa época das passadas:

Até por volta do século XII, a arte medieval desconhecia a infância ou não tentava representá-la; é difícil acreditar que essa ausência se devesse à falta de habilidade ou de competência. Parece mais provável que a infância não tivesse lugar naquele mundo. (Ariès, 1973, p. 23)

Essa análise de Philippe Ariès deve ser confrontada com o recorte cronológico proposto por Régis Debray e, mais particularmente, com as duas primeiras épocas características das produçóes iconográficas humanas que ele propõe: a "logoesfera" ou era dos ídolos (da invenção da escrita até à da imprensa) e a "grafoesfera" ou era da arte (da imprensa até a TV em cores): "Cada uma dessas eras desenha um meio de vida e de pensamento, com conexóes internas estreitas, um ecossistema da visão e, portanto, um certo horizonte de expectativa do olhar" (Debray, 1992, p. 222). Ao caráter rígido e intemporal do ídolo, Debray opõe um começo de movimento das figuras da arte, no registro do adágio.

Ao emancipar-se paulatinamente do teológico para entrar na história, a arte impõe o homem como referente para os olhares: "A imagem humanista emancipa-se do culto, produz sua própria cultura. Ela passa do sacro ao laico, do comunitário ao particular e, embora ainda presa à Revelação primeira, seu valor não está mais indexado à escala dos poderes divinos" (idem, p. 246). E as crianças nisso tudo? Que imagem delas Elisabeth Vigée Lebrun nós dá a ver? 
Loic Chalmel

Figura 1

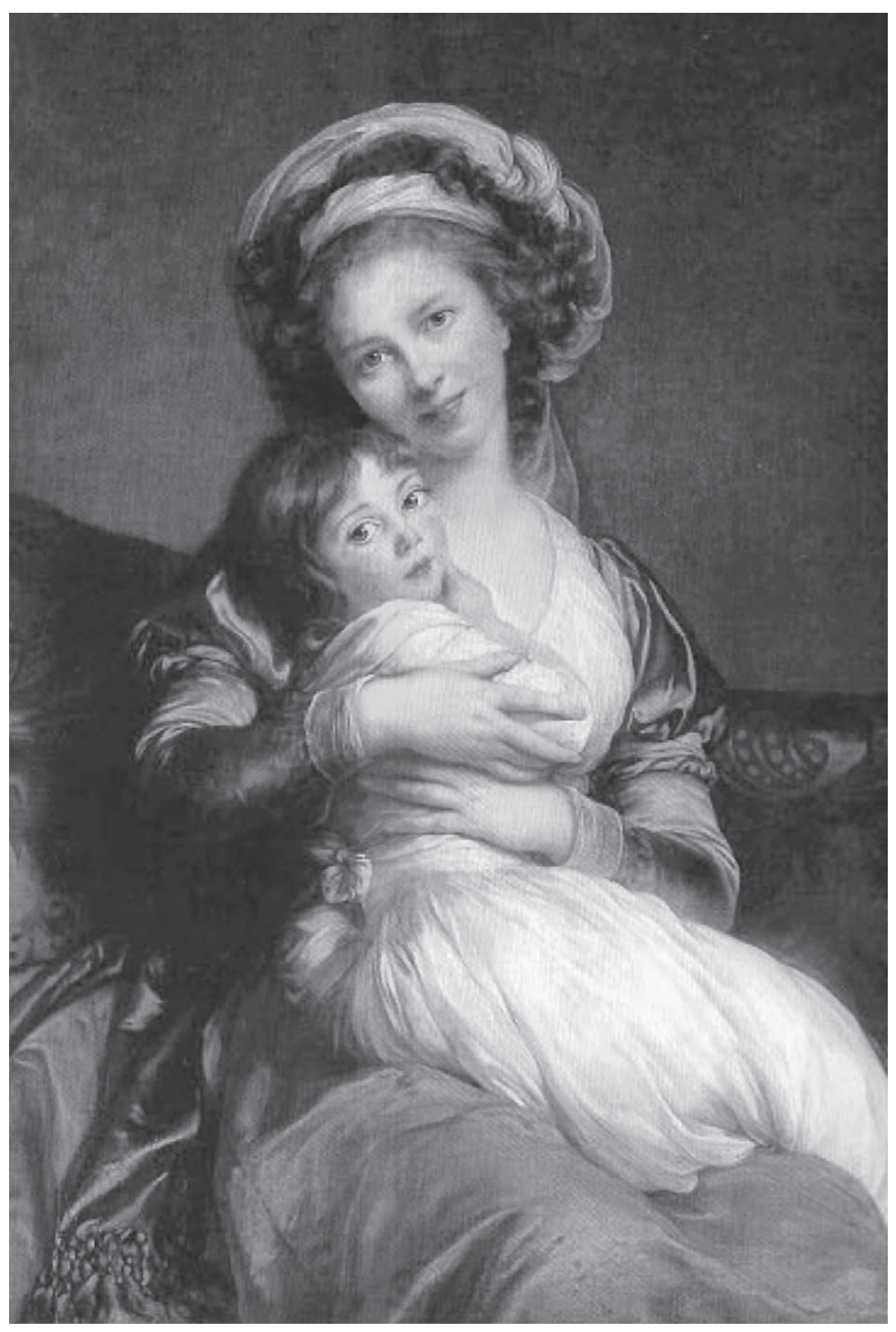

Embora a composição continue inspirada pelo modelo da Virgem com criança, neste Auto-retrato, também chamado de Ternura maternal, o rosto e a atitude de sua filha certamente nada têm a ver com os dos meninos Jesus das madonas de Bellini, cópias de homens sem nenhum traço da infância, que contrastam com a enigmática beleza de sua mãe; Vigée Lebrun não se recusa a representar a morfologia infantil ao reproduzir miniaturas de homens.

Educ. Soc., Campinas, vol. 25, n. 86, p. 57-74, abril 2004 
Imagens de crianças e crianças nas imagens: representações da infância...

Entretanto, nenhuma produção artística escapa por completo à tutela econômica de uma entidade governante: a arte também é governada. O grupo social hegemônico impõe de fato um estilo e imagens, "por ser quem os encomenda, compra e promove, é também, muito naturalmente, o arbítrio das elegâncias e o índice dos valores" (Debray, 1992, p. 254). Assim, à pintura sacra, cujo reinado chega ao fim com o definhamento da potência temporal da Igreja, e às cenas épicas e mitológicas que glorificam monarcas absolutos, sucedem cenas de gênero e retratos representativos do gosto da burguesia rentista. Ao mesmo tempo, as imagens "dadas a ver" diversificam-se com a multiplicação dos olhares: privilégio de príncipes e homens da Igreja, a coleção torna-se particular com os humanistas, e essas duas fontes originais confluem para os museus públicos que se impóem como lugares de olhares coletivos.

Os retratos e outras "cenas de gênero" são particularmente representativos desse gosto burguês: o "realismo" de seus modelos afasta-os da trilogia própria do Ancien Régime proposta por Ariès: o anjo adolescente, o menino Jesus e o putto ou criança nua. Este último, contudo, perdura, na sua nudez decorativa, até a "foto de arte" dos álbuns de família do século XX. Desde os séculos XV e XVI, uma iconografia laica e burguesa da infância substitui assim, progressivamente, a iconografia religiosa, e a maneira como é posta em imagem a divide em duas grandes categorias: representações estáticas de personagens e cenas de gênero. A multiplicação de retratos de crianças sozinhas (sem a presença de seus ascendentes na tela) constitui a verdadeira evolução própria dos séculos XVII e XVIII; o caráter efêmero e transitório desse período da vida humana se torna um dos temas favoritos dos artistas à cata de novidades:

É também no século XVII que os retratos de família bem mais antigos tendem a se organizar em torno da criança, a qual se torna o centro da composição (...). O pintor barroco conta com elas [as crianças] para dar ao retrato de grupo o dinamismo que lhe faltava. Ainda no século XVII, a cena de gênero reservará à infância um lugar privilegiado: há inúmeras cenas de infância com caráter convencional, aulas de leitura, nas quais persiste o tema da aula da Virgem da iconografia religiosa dos séculos XIV e XV, aula de música, moços ou moças desenhando, brincando (...). (Ariès, 1973, p. 38) 
Seria a multiplicação das cenas de gênero representativa de uma realidade social subjacente, ou sintomática de uma moda, de um gosto, ou até mesmo de um objeto de deleite para com a imagem juvenil?

\section{...à criança real}

As concepções da infância e de sua educação escondidas atrás dos rostos dos retratos e outras cenas de gênero erigem Elisabeth Vigée Lebrun e sua filha em ícone: até a idade de sete anos, pelo menos, impõe-se a imagem da mãe educadora. Datado de setembro de 1791, um relatório de Talleyrand (1754-1838) para a Assembléia Nacional francesa constitui o paradigma dessa tendência:

Até a idade de seis, sete anos, a instrução pública mal consegue atingir a infância cujas faculdades são fracas demais, pouco desenvolvidas demais; ela exige cuidados particulares demais, exclusivos demais. Até então foi preciso alimentá-la, cuidar dela, fortificá-la, fazê-la feliz: este é o dever das mães. Longe de contrariar a prescrição da natureza, a Assembléia Nacional a respeitará a ponto de proibir-se toda e qualquer lei a este respeito; ela entenderá que basta lembrar-lhes suas comoventes funções por meio do próprio sentimento de sua felicidade, e pela sua mais clara aprovação consagrar as imortais lições que lhes deu o autor de "l'Emile". (Chalmel, 1996/2000, p. 146)

Ao declarar o filho do homem imaturo, Talleyrand subtrai-o de fato à sociedade dos adultos, e apaga, de certa forma, a clivagem entre ricos e pobres. Embora um pedagogo pudesse concordar com esse político no reconhecimento do papel insubstituível das mães nesses estágios do desenvolvimento da criança, teria mais cautela quanto à concretização de uma relação afetiva equilibrada. Assim, para Jean-Henri Pestalozzi (1746-1827), é mesmo à mãe, na relação privilegiada que estabelece com a criança pequena, que cabe a tarefa de desenvolver em seu coração os sentimentos morais e religiosos fundamentais. Entretanto, afora na imagem, sua presença permanece bem aleatória, independentemente dos meios sociais de origem:

Nos primeiros anos da criança, quando se confia o desenvolvimento de suas faculdades, sem nenhuma ajuda da arte, à grande impulsão da natureza, costuma faltar geralmente, e antes de tudo, uma mãe que, graças a uma formação evoluída de suas próprias faculdades, carregue em si, de 
Imagens de crianças e crianças nas imagens: representações da infância...

maneira consciente, o estímulo ao mesmo tempo vivo, ponderado e amadurecido daquilo que ela deveria ser, naturalmente, para esta criança. (Pestalozzi, 1826/1947, p. 282)

A expressão daquilo que "falta" não é uma palavra vã, muito pelo contrário, se considerarmos as palavras de Pestalozzi à luz do contexto desolador em que se situa seu discurso. De fato, nesse fim do século XVIII, o bebê que vem à luz tem pouco mais que 50\% de chance de ultrapassar o marco dos dois anos. A falta de cuidados e de higiene, a desnutrição e a deficiência da medicina, os abandonos de crianças quando as condições econômicas se tornam duras demais para as classes populares são alguns dos fatores que favorecem essa pavorosa mortalidade... O único remédio conhecido é... ter muitos filhos, e ele é seguido à risca. O estatuto do lactente é pouco invejável: ele incomoda a burguesa nas suas atividades mundanas e estorva a operária obrigada a trabalhar do raiar do sol ao anoitecer: "Das vinte e uma mil crianças que nascem a cada ano, menos de mil são alimentadas por suas mães e mil são alimentadas em domicílio por uma ama. Todas as outras, ou seja, dezenove mil, são confiadas a uma criadeira”. Esta é a terrível conclusão estatística à qual chega, em 1780, Lenoir, tenente-geral de polícia em Paris... Independentemente de seus meios de origem, verdadeiras organizações de aliciamento encaminham as crianças para casas de amas-de-leite mercenárias. Durante o transporte, a mortalidade é grande. Entretanto, essa mortalidade muito elevada, em si, não basta para desculpar a falta de investimento, pelas mães, "na particularidade infantil". Assim a preocupante questão do infanticídio alimenta os debates filosóficos no Século das Luzes:

Infanticídio! Trata-se de um pesadelo ou estou mesmo acordado? - Será esse ato possível? Isto ocorre de verdade? O inominável ocorre - Não, o inominável, não, mas o crime que essa palavra recobre? Vela teu rosto, ô, século! Baixa a cabeça, Europa! A resposta ecoa em teus tribunais. - É aos milhares que meus filhos são mortos pela mão das que os deram à luz (...). $\mathrm{O}$, Europa! O que leva uma mãe a matar sua cria? De onde vem o desespero que se instila no peito da moça? A tal ponto - meu Deus! Que estremece quando do parto! E que na febre da parição ela estende uma mão enfurecida, para sufocar o fruto de suas entranhas. (Pestalozzi, 1782/2003)

Ao se abstrair da realidade econômica e social, o iconógrafo parece, portanto, empenhar-se em representar uma infância de sonhos, 
graciosa e pitoresca, bem ao gosto burguês. A partir do século XVII, o "mignotage" (mimo exagerado) constituirá uma hipertrofia dessa tendência.

A virada do século XIX para o XX e o ingresso na era industrial terão poucas conotações de progresso para os filhos das classes trabalhadoras na Europa. Assim, quando o empresário filantropo Robert Owen (1771-1858) toma, em 1800, as encomendas das fiaçóes de New Lanark (Escócia), que empregam uns mil operários, ele fica impressionado pelo número muito elevado e a situação miserável das crianças que trabalham na fiação:

Constatamos que, no geral, crianças de dez anos trabalhavam regularmente quatorze horas por dia, com apenas meia-hora de pausa para a refeição do meio-dia que tomavam na fábrica. Nas fiações de algodão fino, elas eram obrigadas a esse trabalho numa temperatura que costumava ultrapassar os $42^{\circ}$; e em todas os fábricas de algodão, elas respiravam uma atmosfera mais ou menos deletéria para os pulmões por causa do pó e das minúsculas fibras de algodão nela espalhadas... Obviamente, esse sistema não podia ser mantido sem castigos corporais. A maioria dos vigias carregava abertamente temíveis cintas de couro, e em várias oportunidades, os vimos bater nas crianças com muita força, até mesmo nas menores. (Chalmel, 1996/2000, p. 250)

As novas condições econômicas e sociais geradas pela Revolução Industrial tiveram impactos na organização familiar, principalmente por meio do trabalho das mulheres e das crianças nas fiações. Para complementar as rendas do chefe de família, muitas eram empregadas 14 horas por dia em trabalhos pesados. As conseqüências dessas longas ausências sobre a educação são inevitáveis. Elas incitam outro filantropo, Daniel Legrand (1783-1859), precursor das leis internacionais sobre os direitos da criança, a fazer votar, em 1841, uma lei que restringe o emprego de crianças nas fábricas:

As mecânicas prendem populaçôes inteiras em suas engrenagens, de idosos a crianças. A água e o vapor as mantêm num movimento contínuo e, conseqüência necessária dos grandes capitais nelas investidos, o cálculo da cupidez apenas será perfeito quando esse movimento não tiver mais interrupçôes, e se terá apagado a distinção entre o que ainda chamamos de dia e noite, seis dias de trabalho e um santo dia de repouso, para essas pobres e infelizes vítimas, que, privadas de direitos naturais e inalteráveis, não terão mais tempo a dedicar ao repouso, à saúde, à instrução e ao culto. (Monnier, 1908, p. 9-10) 
Imagens de crianças e crianças nas imagens: representações da infância...

A luta para "salvaguardar a infância" continua até o fim do século XIX, como mostra a diatribe de Pauline Kergomard (18381925), fundadora da escola maternal francesa, contra a negligência, o desprezo, a indigência intelectual e material que é o fado dos filhos das classes trabalhadoras:

Sob pretexto de que, durante toda a sua vida, o homem é exposto ao padecimento físico, às provaçóes, aos dissabores, estão quase a ponto de inventar sofrimentos físicos, provações, dissabores para a criança... Levar esse sistema a suas últimas conseqüências exigiria uma coisa: matá-las primeiro, sob pretexto de que acabarão morrendo um dia. (Kergomard, 1886, p. 3)

Significaria isto que as representações da infância no século XVIII nada trazem de novo? Muito pelo contrário! Apesar do cenário sombrio descrito acima, esse século de fervor intelectual sem precedente vê sucederem-se, coexistirem, entremearem-se intimamente, às vezes até de modo barroco e inesperado, com um descompasso ou certos matizes segundo os diferentes países europeus, correntes de pensamento tão diversas como: o humanismo tardio, as Luzes alemãs ou Aufklärung, os pietismos de primeira e segunda geração, o racionalismo crítico bem como o misticismo irracional, o Sturm und Drang, que desembocaria no romantismo, tudo isso dominado por aspirações à "Reforma”, fermento de uma revolução, à qual se seguiriam, na França, nacionalismo e restauração. O Emile, de Jean-Jacques Rousseau, sintetiza essa nova abordagem da criança, então vista como portadora de potencialidades em devir e de um valor intrínseco, cuja natureza e necessidades é preciso empenhar-se em conhecer. $\mathrm{O}$ apego à criança e a suas particularidades não se exprime mais pela diversão ou o brincar, mas pelo interesse psicológico e pela preocupação moral. Entretanto, o vínculo entre as considerações filosóficas e suas conseqüências na iconografia da época permanece tênue. Daí a idéia de um desvio, por parte dos pedagogos, especialistas da infância por vocação, e, mais particularmente, por aqueles que atribuem uma importância determinante às imagens no processo de aprendizagem.

\section{A imagética dos pedagogos}

Escolhemos nos referir aos trabalhos de dois deles, o checo Jean Amos Komensky (1592-1671), mais conhecido pelo nome de 
Comenius, para o século XVII, e o alemão Jean-Bernard Basedow (1723-1790) no que tange ao século XVIII. Essas duas grandes figuras da história das idéias educativas têm em comum um certo gosto pela imagem e sua oposição ao pensamento agostiniano segundo o qual a criança, força do mal, deve ser endireitada.

A relação entre imagem e pedagogia será aqui apreendida segundo duas perspectivas: a imagem da criança e a imagem para as crianças ou, melhor dizendo, a imagem para ver e a imagem dada a ver. No primeiro caso ela é sujeito, no segundo, ela se torna objeto.

Comenius procura antes de tudo tornar acessível a todos uma mensagem de alcance universal. Por isso, dirige-se a cada um e lança mão de tudo o que pode. Ele desenvolve os fundamentos ideológicos de sua pedagogia principalmente nos quatro primeiros capítulos de sua Didática magna. No capítulo III, em particular (Comenius, 1657/1992, p. 53), ele afirma que a vida terrestre nada mais é que um preparo para a vida eterna. E em suas trocas com o mundo, criação da infinita sabedoria divina, que o homem encontra, ao longo de sua existência, o alimento espiritual necessário à salvação:

Buscamos Deus observando os sinais de sua divindade por meio do conjunto da criação... Tríplice é a fonte da qual extraímos essa disposição da alma... Essa fonte consiste:

1. nas Santas Escrituras,

2. no Mundo,

3. em nós mesmos;

isto é, no primeiro caso, na própria palavra de Deus; no segundo, nas suas obras; no terceiro, na sua inspiração em nós. Certamente, das Escrituras extraímos o conhecimento e o amor de Deus. Do mundo e da inteligente contemplação da obra admirável de Deus nele, somos levados ao sentimento de devoção. (Comenius, 1657/1992, p. 53)

Desse modo, o homem é capaz de apreender na criação a marca do Divino. Um campo imenso descortina-se assim pra o estudo: tratase de analisar a criação em todas as suas dimensões, estabelecer distinções e classificações, apreender as relações entre as coisas. Desenham-se então os contornos de uma formação cuja pretensão só pode ser universal, assim como a própria criação é universal. $\mathrm{O}$ fato de conceituar o mundo como uma escola leva a buscar sua penetração em todas as suas 
Imagens de crianças e crianças nas imagens: representações da infância...

particularidades. Essa busca de verdade é facilitada pela bivalência do indivíduo, ao mesmo tempo objeto e sujeito do mundo: ele é objeto num universo do qual é parte integrante e sujeito que age para compreender seus mecanismos e interpretá-los. A aquisição da linguagem representa um desafio maior numa tal perspectiva, e Comenius recomenda aos educadores que progridam paulatinamente associando sempre, com os jovens espíritos, o nome de um objeto à sua forma real ou, quando impossível, à sua imagem. Como, na sua época, não existem livros que apresentem às crianças imagens do mundo, ele mesmo elabora, segundo uma progressão coerente, uma primeira obra documentária ilustrada, única em seu gênero: Orbis pictus.

Publicado em 1685, em Nuremberg, o "Mundo sensível ilustrado" (Orbis sensualium pictus) é o primeiro livro escolar em que a imagem desempenha um papel fundamental na aquisição do saber. Pela primeira vez, mais que o texto, a imagem é fonte de conhecimentos. Esse livro representa o auxiliar indispensável para substituir muitos elementos do mundo sensível que o pedagogo não pode levar à sala de aula. A imagem parece assim o paliativo privilegiado quando não se pode pôr o aluno em situação de manipular diretamente um objeto a ser compreendido ou simplesmente nomeado; essa iniciação ao mundo real pela imagem é necessária se aceitarmos a teoria comeniana da aprendizagem segundo a qual o sensível é inseparável do intelectual, o conceito da imagem e o objeto real da palavra que o descreve:

Entretanto, no mais das vezes, ignora-se e faz-se pouco caso disto nas escolas, e propóe-se aos alunos aprenderem coisas das quais nada entendem, e até mesmo que seus sentidos mal saberiam imaginar: donde tanto o trabalho de ensinar como o de aprender terem pouco êxito. (Comenius, 1685, p. 4)

Ele explica então como esta obra, "Compêndio do mundo inteiro e de toda a língua, enfeitado e enriquecido por pinturas, nomenclaturas e descriçóes de mil e mil coisas" (Comenius, 1685, p. 4), foi elaborada. As pinturas almejam mostrar com perfeição todas as coisas visíveis e propor uma representação de certas coisas invisíveis; as nomenclaturas exprimem "com uma palavra geral o tema conteúdo" (das pinturas); graças a um sistema de remissóes numeradas presentes sobre a imagem, as descrições permitem um vaivém entre o texto explicativo e a coisa descrita. Embora convencido da utilidade de sua obra para permitir às crianças de seu século uma experiência do mundo mais jus- 
ta e completa, ele não deixa de ter consciência de suas limitações e aconselha sempre apresentar o objeto real antes de recorrer à imagem: "Algumas das coisas acima mencionadas não podem ser representadas ao olho, por exemplo, as cores, os sabores etc. (impossíveis de se retratarem com tinta de caneta)? Seria um ótimo expediente mostrá-las em si, em particular aos alunos" (Comenius, 1685, p. 6). Para concluir essa breve apresentação, pode-se afirmar que a Orbis pictus constitui, no percurso teórico do bispo morávio, uma síntese de suas reflexôes sobre a aquisição do saber. Tanto pelo seu conteúdo como pela sua redação sistemática em várias línguas (quadrilinguis), esta ferramenta didática com vocação universal acompanha o aluno ao longo de todo o seu percurso educativo. Nela, ele aprende sucessivamente a reconhecer e nomear objetos que lhe são mais ou menos próximos, a designá-los pelo nome, a ler, a compreender mecanismos biológicos ou físicos mais ou menos complexos, tudo sob o olhar condescendente do Criador.

A página 2 da edição de 1685 permite-nos trazer nossa discussão de volta à representação da criança: sob o título "Invitatio", o autor dá-nos a ver a seguinte imagem da relação pedagógica:

\section{Figura 2}

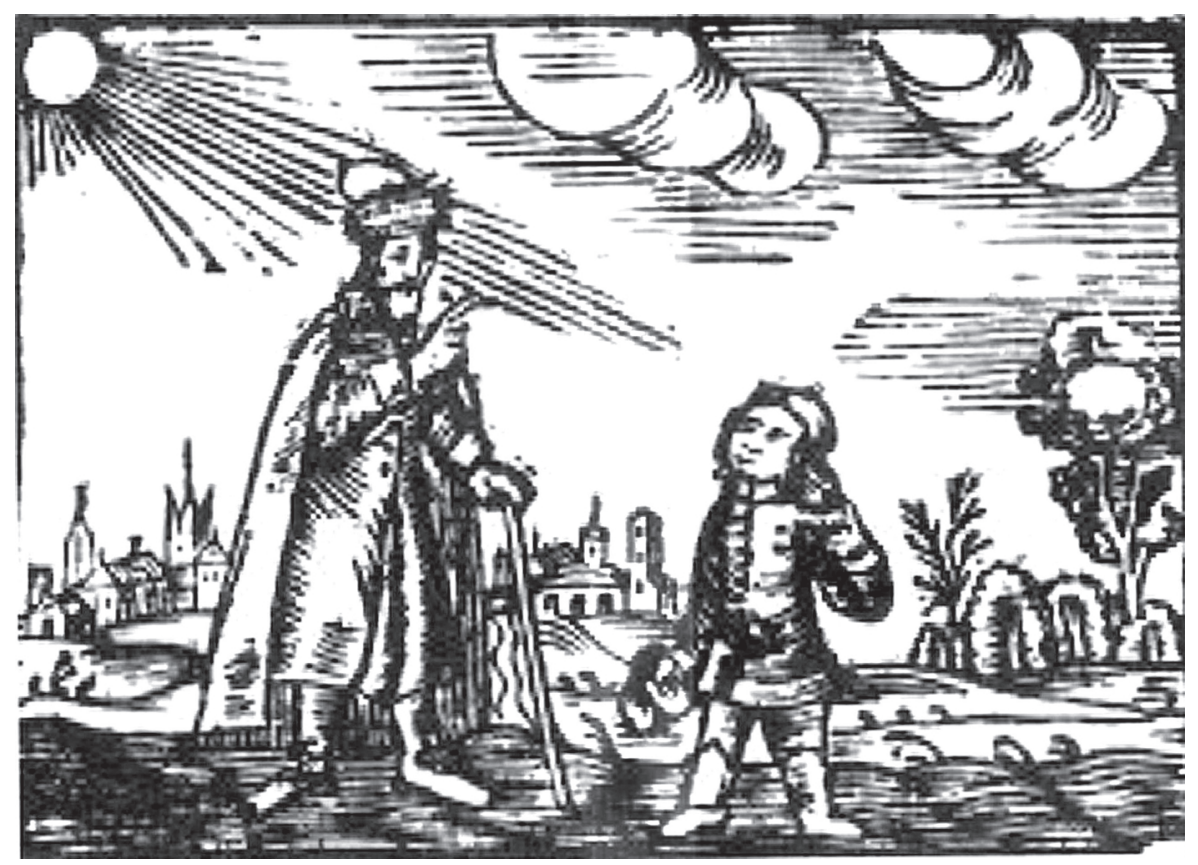

Educ. Soc., Campinas, vol. 25, n. 86, p. 57-74, abril 2004 
Imagens de crianças e crianças nas imagens: representações da infância...

Sua composição é particularmente representativa do pensamento educativo de Comenius:

- a aula ocorre no exterior, em contato direto com o meio ambiente natural, um dos três "livros" nos quais o homem é convidado a encontrar seu Criador;

- o pedagogo e a criança parecem vinculados pela palavra, o discurso do primeiro encarna a sabedoria (lembrança da mão do Cristo, que ensina), o segundo aponta para sua orelha, meio de acesso privilegiado para o saber, junto com a visão e o tato;

- de ambas as partes, a cena organiza-se numa diagonal que, acompanhando os raios do sol, perpassa a mente do pedagogo e a da criança, indicando claramente a origem divina do saber. Abaixo desta, a luz, a vida, as construções humanas; acima dela, as nuvens, a bruma como tantos sinais de ignorância.

A imagem da criança aprendendo proposta por Comenius antecipa concepçôes modernas da educação, numa época em que os mais jo-

Figura 3

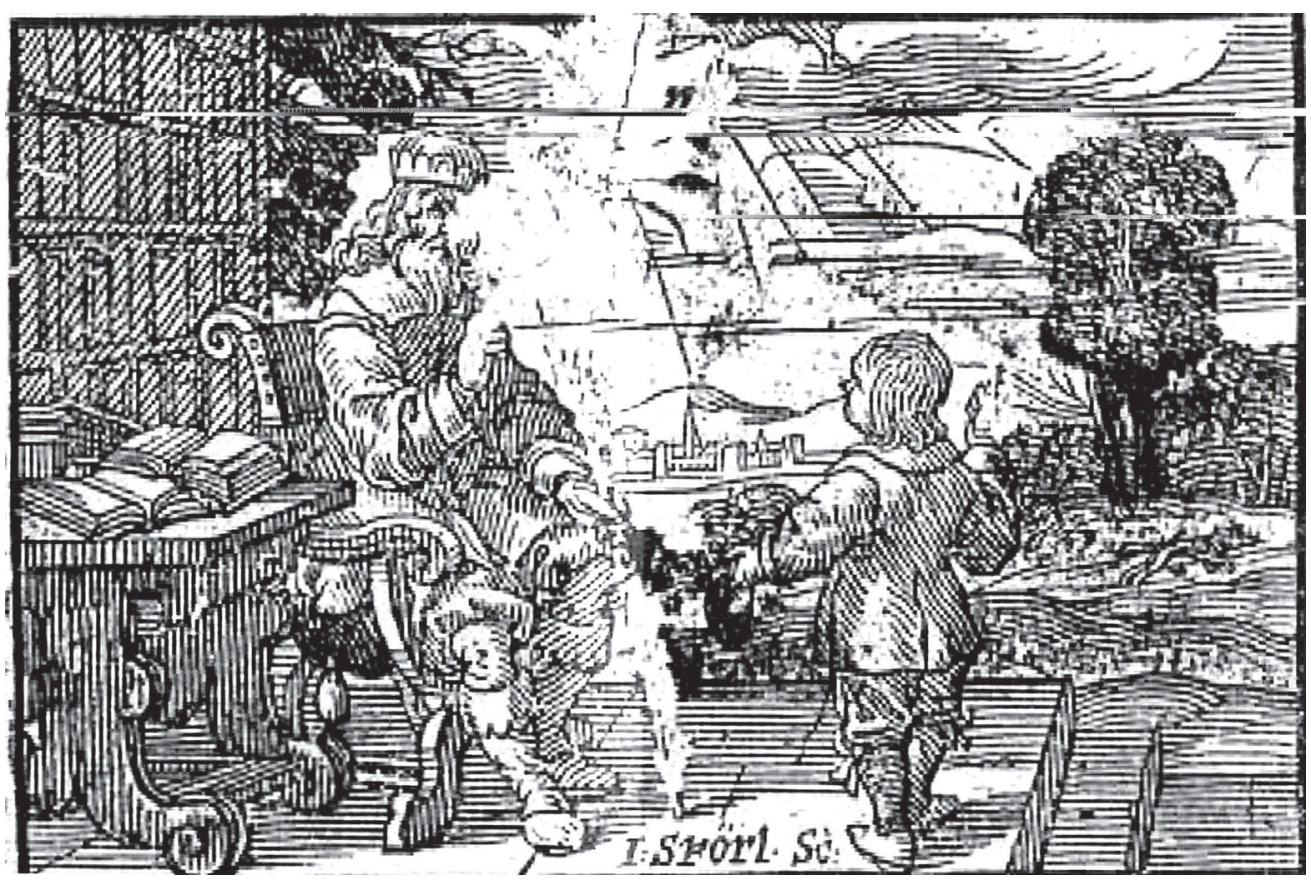


vens não têm o mínimo estatuto na sociedade dos homens, como vimos anteriormente. Embora permaneça de forma clara conotada teologicamente, ela gera a abertura, a alegria, o respeito, no cerne de uma pedagogia do despertar para os mundos internos e externos. Pouco conforme ao gosto burguês dos países latinos, ela só pode incomodar. Assim, numa tradução em francês e em italiano do começo do século XVIII, embora o editor tenha conservado o texto original, modificou algumas imagens. Eis como ficou "o convite" feito pelo pedagogo à criança:

A retórica da imagem em nada corresponde aqui a um arranjo do espaço-tempo das aprendizagens, para "modernizar" uma representação julgada obsoleta: ela constitui uma verdadeira inversão de paradigma:

- a aula valida um início de clausura, sendo a natureza relegada ao segundo plano, nitidamente suplantada pela presença maciça de livros (aos quais, por sinal, a criança não parece ter acesso direto), que substituem o sol, fonte da diagonal que dividia a imagem original;

- a relação entre o adulto e a criança é claramente do tipo dominante-dominado: presença de escadas para se ter acesso ao saber, posição sentada de um pedagogo coroado como um príncipe, função ambígua da bengala que ele segura na mão esquerda (palmatória?), necessidade para a criança de se descobrir e de pedir a palavra...

Certamente, as referências religiosas dissipam-se nesta segunda representação. Será que isso, em si, permite-nos associar essa secularização a um progresso? A clausura substitui-se à abertura, os estudos livrescos à exploração natural, a coerção e o esforço à vontade... em matéria de pedagogia, assim como em outras, é preciso evitar associar o conceito de novidade ao de modernidade. Assim, a coletânea de estampas de Daniel Chodowieki, complemento indissociável do Elementarwerk publicado em 1774 pelo pedagogo "filantropinista" alemão Jean-Bernard Basedow, também é considerada uma melhoria da idéia original de Comenius:

Já no século XVII, na Alemanha, o Sr. Comenius propõe substituir, na instrução da juventude, o conhecimento das palavras pelo das coisas, e seu Orbis pictus, com gravuras em madeira, dava uma amostra disto. A execução imperfeita dessa idéia preciosa num século ainda meio bárbaro era um dia- 
Imagens de crianças e crianças nas imagens: representações da infância...

mante bruto, ao qual M. Basedow, o J.-J. Rousseau dos alemães, deu mais esmero, em torno do fim do século passado, em seu livro elementar, ilustrado com talhos-doces. O "Portefeuille des enfants", publicado em Paris, é uma sua imitação. Essas empreitadas obtiveram tanto sucesso quanto poderiam esperar particulares entregues a si mesmos, e cujo zelo louvável não foi encorajado. (Simon, 1801, p. 19-20)

Para melhor compreender as relações que unem representação

Figura 4

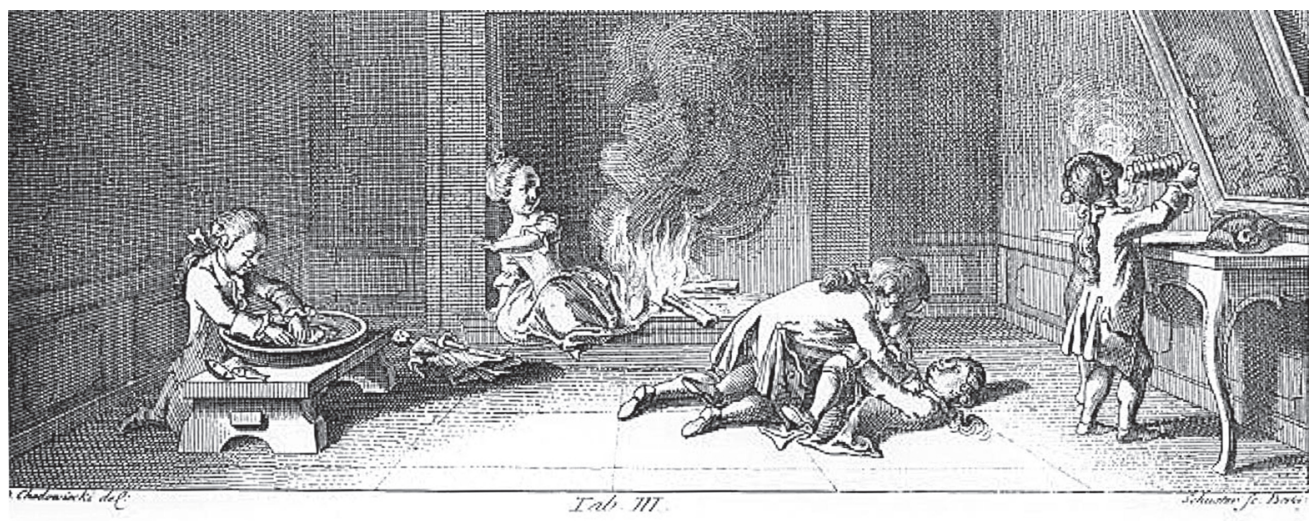

da criança, imagem e pedagogia, deixaremos o leitor observar o quadro n. III da coletânea original, de 1774:

Aqui, estamos claramente diante de uma cena de gênero (as travessuras das crianças), afinal, muito conforme ao gosto burguês do século XVIII. O fato de Basedow não ter feito pessoalmente essas gravuras, como fizera seu predecessor, mas de ter recorrido a um artista de renome (Chodowieki), não é alheio a esse resultado. As crianças representadas estão todas em situação de transgressão das regras, e vão ter de suportar as conseqüências disso. Para os "filantropinistas", a utilização da imagem continua essencial para implementar um método "praticável por conversas sobre todas as coisas presentes para os alunos e sobre os objetos que, desenhados pelo Sr. D. Chodowieki para a obra elementar do Sr. Basedow, encontram-se nas cem gravuras (...)" (Wolke, 1782). De fato, a utilização da imagem continua essencial para implementar o método de Basedow, herdeiro, nisso, do pensamento educativo fecundo de Komensky. A diferença fundamen- 
tal entre a Orbis pictus e essa Antologia de gravuras está no plano da interatividade entre o texto e a imagem, o significante e o significado. Explícita em Comenius, essa suposta interatividade se torna implícita nos filantropos. De fato, Komensky empenhou-se para integrar na sua obra todas as ferramentas necessárias ao pedagogo ou à criança, num procedimento de autoformação, para construir suas aprendizagens ou desenvolver sua curiosidade. As imagens do mestre morávio são construções didáticas que respondem a um princípio imutável: partir daquilo que o aprendiz conhece e apoiar-se nesse capital para lhe trazer conhecimentos novos. $\mathrm{E}$ isso tanto no plano das conquistas lingüísticas como no da leitura da imagem ou ainda de sua interação mútua. Os filantropos não constroem suas imagens pessoalmente, mas recorrem a um artista de renome, introduzindo assim uma dimensão plástica no seu projeto. A interatividade é aqui criada pela palavra do mestre e a solicitação constante do olhar dos alunos. O comentário proposto a seguir permite-nos ter uma idéia mais precisa dessa função de condução do olho:

Tu, menininho tão elegantemente vestido, cuidas muito pouco da própria limpeza: ajoelhas-te diante daquele estrado e derramas, com as tuas mãos, a água que está na bacia. Faça antes boiar esse barquinho e o peixe de madeira, que estão à tua esquerda no estrado. E tu, pequena imprudente! Sentastes perto demais do fogo da lareira. Agora, queres fugir; apavorada, jogas tua boneca no chão; chamas homens feitos para que te acudam! Venham, meu caro papai, minha cara mamãe, meus caros irmãos! Venham, meus amigos que estão me ouvindo! Socorro! Ah, socorro, salvem-me! Meu vestido pegou fogo! Vai me queimar! Venham depressa apagar as chamas com água, ou senão minha pele, minha carne, meus nervos vão pegar fogo e me causar violentas dores. - Eis o que acontece com quem não toma cuidado com as chamas etc. (Wolke, 1782)

Portanto, o procedimento do "premonstrador" é mesmo o de "dar a ver" à criança, e a palavra guia o olhar, num vaivém incessante entre o conjunto e as partes, com uma preocupação especial para com o detalhe. $\mathrm{O}$ mestre associa em seu comentário em língua estrangeira contribuições lexicais, sintáticas e considerações morais. Uma vez que ser "premonstrador" não se improvisa, é preciso juntar à "Coletânea de gravuras” um guia pedagógico em forma de comentários. 
Imagens de crianças e crianças nas imagens: representaçōes da infância...

\section{Tecer sentido}

Tanto Basedow como Comenius desejam ardentemente uma difusão universal dos conhecimentos enciclopédicos, sistematizados e organizados, ao alcance dos públicos em formação. Neste sentido, a imagem representa uma mídia insubstituível para alcançarem seus fins. Entretanto, as variaçōes estilísticas não deixam de ter impactos sobre a natureza dos conceitos "a serem adquiridos" e das representações da infância veiculadas. $\mathrm{O}$ estilo próprio de uma época, julgado obsoleto, parece sempre ter precisado de modernização. Essa idéia de estilo particular a cada geração deve ser aproximada do efeito de moda precedentemente descrito; melhor dizendo, ele participa da tecedura do hipertexto, segundo a definição de Lévy (1990), possibilitando a partilha de sentido no cerne de uma coletividade humana num dado momento:

Para que as coletividades compartilhem sentidos, não basta, portanto, que cada um receba a mesma mensagem (...). Assim, encontra-se dada a ver e como que materializada a constituição do sentido comum: a elaboração coletiva de um hipertexto (...). O fundamento transcendental da comunicação, compreendida como partilha de sentido, é esse contexto ou esse hipertexto compartilhado (...). Portanto, o objeto principal de uma teoria hermenêutica da comunicação não será nem a mensagem, nem o emissor, nem o receptor, mas sim o hipertexto, que, como uma espécie de nicho ecológico, é o sistema sempre movediço das relações de sentido que eles mantêm entre si. E os principais operadores desta teoria não serão nem a codificação nem a decodificação nem a luta contra o barulho através da redundância, mas sim essas operações moleculares de associação e dissociação que realizam a metamorfose perpétua do sentido. (Lévy, 1990, p. 81)

O principal interesse de uma comparação das representações da infância por meio das imagens dos pedagogos encontra-se verdadeiramente nessa abordagem hermenêutica da comunicação, que considera a associação de idéias uma operação elementar da atividade interpretativa. Para que uma imagem faça sentido, é preciso vinculála, conectá-la com outras, construindo com isso um hipertexto. Assim, em função do conhecimento das práticas educativas, do sistema de valores de referência e dos conhecimentos teóricos de cada um, o hipertexto pode diferir completamente na leitura de um quadro entretanto único. A rede de relaçôes em que a imagem estará presa é determinante a este respeito. Tal comunidade intelectual ou educativa 
constituída, aval de um certo número de valores, estará, então, mais ou menos disposta a acolher um modelo educativo de outra época, nem que seja apenas para questioná-lo. As gravuras apresentadas constituem um exemplo particular dessas flutuações.

Essas consideraçōes nos trazem de volta à nossa problemática inicial: será que o Século das Luzes na Europa constituiu um período-chave na evolução das concepções da criança na arte em geral? Depois do que acaba de ser escrito, preferimos dizer que os modos de representação da infância aqui expostos estão estreitamente vinculados a uma simbólica própria da comunidade intelectual dominante, garantia dos valores burgueses de referência. Os retratos de crianças e outras cenas de gênero preocupam-se muito pouco em refletir as realidades sociais ou educativas de seu tempo; geralmente, constituem uma imagem estereotipada e idealizada que circula entre os espíritos da época:

Imaginemos que as imagens, os enunciados, as idéias (que agruparemos sob o termo genérico de representações) sejam vírus. Esses vírus particulares habitariam o pensamento das pessoas e se propagariam de um espírito a outro por todos os meios de comunicação (...). Em sua maior parte, os fenômenos culturais inscrevem-se numa epidemiologia das representações. Uma cultura poderia então identificar-se com uma certa distribuição de representaçôes numa população dada. (Lévy, 1990, p. 158)

Tomara, para concluir, que um exame atento das obras disponíveis nos ajude, por contraste, a questionar nossa epidemiologia contemporânea das representações da infância.

Recebido e aprovado em fevereiro de 2004.

Referências bibliográficas

ARIÈS, P. L'enfant et la vie familiale sous l'Ancien Régime. Paris: Seuil, 1973.

CHALMEL, L. La petite école dans l'école. Bern: Peter Lang, 1996, 2000.

Educ. Soc., Campinas, vol. 25, n. 86, p. 57-74, abril 2004 
Imagens de crianças e crianças nas imagens: representações da infância...

COMENIUS, J.-A. La grande didactique. Paris: Klincksieck, 1657, 1992.

COMENIUS, J.-A. Orbis sensualium pictus quadrilinguis. Leutschovle: Samuel Brewer, 1685.

DEBRAY, R. Vie et mort de l'image: une histoire du regard en Occident. Paris: Gallimard, 1992.

KERGOMARD, P. L'éducation maternelle dans l'école. Paris: Hachette, 1886.

LÉVY, P. Les technologies de l'intelligence. Paris: La Découverte, 1990.

MONNIER, F. Notice sur Daniel Legrand. Le Cateau: Rolland, 1908.

PESTALOZZI, J.-H. Sur la législation et l'infanticide. Bern: Peter Lang, 1782, 2003.

PESTALOZZI, J.-H. Le chant du cygne. Neuchâtel: La Baconnière, 1826, 1947.

SIMON, J.-F. Observations sur l'organisation des premiers degrés de l'instruction publique; par Simon, ex-professeur d'allemand au prytannée de Saint-Cyr. Paris: Levrault, 1801.

WOLKE, C.-H. Méthode naturelle d'instruction. Leipzig: Crusius, 1782 . 